ARTIGO TEMATTICO: ESTADO, ECONOMIA E DEMOCRACIANO BRASIL E AMÉRICA LATINA

\title{
O choque neoliberal e o padrão de hegemonia burguesa do lulo-petismo
}

\author{
Claudia Maria Costa Gomes \\ Universidade Federal da Paraíba, Departamento de Serviço Social, Programa \\ de Pós-Graduação em Serviço Social, João Pessoa, PB, Brasil (UFPB)
}

\section{O choque neoliberal e o padrão de hegemonia burguesa do lulo-petismo}

Resumo: O objetivo do artigo é apresentar uma meta-síntese da economia política do lulo-petismo. Trata-se do resultado parcial de projeto de pesquisa e se insere na discussão mais geral sobre desenvolvimento econômico com foco nas relações do Estado brasileiro no último decênio. As aproximações sucessivas ao tema levaram a apreender as contradições entre as frações de classe do bloco no poder e o governo Lula. A análise da totalidade social é pressuposto da investigação com base teórico-metodológica na crítica da economia política, através da utilização da pesquisa bibliográfica e documental, com base no novo-desenvolvimentismo na Era Lula (2003-2016), atentando para as condições econômicas, políticas e sociais do Brasil nesse lapso temporal. Conclui-se que a crise internacional do capital desde 2008 assinala consequências drásticas para as economias latino-americanas e com o fim do ciclo das commodities fez regredir a afluência social do neodesenvolvimentismo no país.

Palavras-chave: Economia política. Capitalismo brasileiro. Neodesenvolvimentismo.

\section{The Neoliberal Shock and the Standard of Bourgeois Hegemony in the Lula-Worker's Party} Government

Abstract: The purpose of this article is to present a meta-synthesis of the political-economy of the administrations of President Lula and his Workers Party. It is the partial result of a research project and is part of a broader discussion about economic development with a focus on relations of the Brazilian state in the past ten years. Various approaches to the issue have allowed understanding the contradictions between the factions of class of the block in power and the Lula government. The analysis of the social totality is a presumption of the investigation whose theoretical methodological base is a criticism of the economic policy through the use of bibliographic and documentary research, based on the neo-developmentalism of the Lula era (2003-2016). It focuses on the economic, political and social conditions of Brazil in this time period. The article concludes that the international crisis of capital since 2008 had drastic consequences for the Latin American economies and with the end of the cycle of commodities, caused regression in the social affluence of neo-developmentalism in the country.

Keywords: Political economy. Brazilian capitalism. Neo-developmentalism.

Recebido em 15.06.2017. Aprovado em 05.09.2017. Revisado em 27.11.2017.

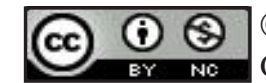

(C) O(s) Autor(es). 2018 Acesso Aberto Esta obra está licenciada sob os termos da Licença Creative Commons Atribuição-NãoComercial 4.0 Internacional (https://creativecommons.org/licenses/bync/4.0/deed.pt_BR), que permite copiar, distribuir e reproduzir em qualquer meio, bem como adaptar, transformar e criar a partir deste material, desde que para fins não comerciais, e que você forneça o devido crédito aos autores e a fonte, insira um link para a Licença Creative Commons e indique se mudanças foram feitas. 


\section{Introdução}

O artigo é resultado de pesquisa aprovada com recursos do CNPq/MCT/UNIVERSAL/2014-2017, intitulada $O$ Neodesenvolvimentismo brasileiro e o programa de reformas de combate à pobreza na era Lula (GOMES, 2014) e integra os estudos desenvolvidos no âmbito do Grupo de Estudos e Pesquisas em Economia Política e Trabalho (GEPET). Tem como objetivo apresentar uma meta-síntese da economia política do lulo-petismo.

Parte-se do pressuposto de que o desgaste social, político e econômico causado por ajustes neoliberais na América Latina apresentam novas mediações referentes à configuração das relações entre o Estado e as classes sociais na transição para o século XXI. Essas mutações no modelo de desenvolvimento do capitalismo brasileiro sui generis, marcado por uma formação social heterônoma (FERNANDES, 2006), se constitui como a síntese recente do chamado neodesenvolvimentismo, um termo que se refere à economia política do lulo-petismo ${ }^{1}$, o qual é objeto desta reflexão.

Salvaguardados a heteróclita tradição marxista, importantes intelectuais tem se dedicado à interpretação e à formulação sobre a atual quadra histórica do capitalismo brasileiro no contexto da crise mundial. Não cabe neste espaço entrar no debate diverso das glosas críticas realizadas e pesquisas vastamente publicadas nesse campo temático, mas apontar os elementos de composição desta experiência, como uma espécie de meta-síntese do lulismo, que no nosso entendimento resulta da contradição entre a formação do capitalismo tardio (1964), as demandas civilizatórias (1988) e o choque neoliberal (2003), que se cristalizaram por meio do Estado e das relações com as frações de classe no poder, através do padrão de hegemonia burguesa instaurada na Era Lula (2003-2016).

Com esse entendimento, parte-se do pressuposto de que o Brasil experimenta no transcurso do século XXI uma configuração política peculiar, com o ensaio neodesenvolvimentista (SINGER, 2016) que culmina com a tentativa lulista de instituir um tipo de economia política de caráter progressista e retributivo, sem alterar os pilares centrais da macroeconomia neoliberal consolidada no período anterior, com o qual resultou em última instância, em uma experiência fracassada, nos marcos do capitalismo dependente e periférico em razão da própria posição subalterna em que o país ocupa na divisão internacional do trabalho, sob o domínio do capital financeiro imperialista.

Esta caracterização do momento comporta elementos de um debate mais fundante do ponto de vista da crítica da economia política, o que significa analisar estrutura e conjuntura, sob as quais emergem e se desenvolve a crise capitalista brasileira, assinalando particularidades do percurso lulista e dados de realidade que permitam desentranhar as contradições da vida política nacional.

A rigor, pode-se dizer que o conjunto dessas mudanças como referência ao pragmatismo político e econômico que se instalou no Brasil, como parte constitutiva da hegemonia neoliberal, corresponde a uma estratégia de passivização do Estado, numa direção clara de construção de contra tendências e busca de espaço para a valorização do capital, que procura reverter a crise de acumulação sob a lógica da dialética do capital fictício, com a criação de instrumentos financeiros e desregulação e abertura dos mercados de derivados².

Nesse sentido, a tarefa que traduz a súmula incorporada pelo neodesenvolvimentismo foi combinar crescimento econômico com melhorias no padrão distributivo do país, operado por uma frente política com frações de classe da burguesia do bloco de poder neoliberal (burguesia produtiva interna e fundos de pensões articulados com o capital financeiro), pelo modo de regulação lulo-petista, garantindo a reprodução do capitalismo periférico, com uma matriz econômica que combine investimento público de cariz neokeynesiano, ativismo estatal com vistas a reindustrialização, mais subsídios aos investimentos privados via desonerações, distribuição de renda e redução da pobreza no país.

$\mathrm{O}$ artigo está estruturado sinteticamente em três partes. A primeira aborda o período de crise e ajuste neoliberal sob as exigências da acumulação capitalista financeira (resultado da valorização da taxa crescente de lucros), que expressam as políticas do consenso de Washington, a regressão social e o ataque aos direitos sociais e democráticos, reverberados em escala mundial entre 2007-2008. São apresentadas as medidas de enfrentamento da crise orgânica (GRAMSCI, 2002), as quais geraram a necessidade de recomposição e adequação entre as forças produtivas e os aparelhos de hegemonia. A segunda parte trata do atual estágio de desenvolvimento capitalista brasileiro, designado por neodesenvolvimentismo. Nessa sessão, o esforço consiste em fazer uma síntese do governo de coalisão, definido como lulo-petismo, para expressar o padrão de hegemonia burguesa da Era Lula. Levanta questões não só de ordem teórica e analítica, mas problemas expressivos de relevância para a dinâmica das classes sociais em luta. A última parte aponta breves considerações finais demonstrando que o modelo de desenvolvimento no Brasil nos marcos da regulação lulista, apenas promoveu uma inflexão do modelo neoliberal em função dos benefícios do boom das commodities, quando o ensaio desenvolvimentista inerme dominou o panorama brasileiro, recuando ante o agravamento da 
crise em 2008, levando a compreender as contradições que se apresentaram nas relações entre o Estado, as frações de classe do bloco no poder e o governo Lula, numa perspectiva de confronto dos elementos da economia política nacional com os interesses hegemônicos das frações de classe em presença.

\section{Expansão capitalista, crise orgânica e acumulação sob a hegemonia financeira}

Como ponto de partida para apreender as determinações que indicam a história recente do Brasil é imperativo referenciar, ainda que de modo conciso, o atual estágio de acumulação capitalista. Trata-se do esforço em analisar a movimentação burguesa a partir de seus projetos e os impactos que incidem sobre os direitos do trabalho e a luta de classes.

Nesse sentido, parece lógico que uma análise de conjuntura deva partir de uma apreciação do cenário mundial. Toma-se, por exemplo, a afirmação de que há uma crise econômica mundial, com perspectivas de agravamento. Essa caracterização do momento comporta elementos de um debate mais estrutural do ponto de vista econômico, político, social e ideológico, o qual pressupõe o conceito de crise que abrange uma variedade de significados, que se pode encontrar em análises marxistas de diversas procedências e fundamentos.

Da crítica da economia política recolhe-se os elementos fundantes para saber que as crises acompanham a dinâmica da acumulação capitalista e possuem uma causalidade determinada, expressando a contradição mesma e inerente desse modo de produção, conformada nessa quadra histórica atual, como um depressed continuum, a qual apresenta características endêmicas, cumulativa, crônica e permanente (MÉSZÁROS, 2009).

O ponto de partida ou contexto dessa conjuntura de crise é evocado pelo processo de expansão do capital nos marcos do neoliberalismo e ratifica os seus vincos com o ordenamento da produção e reprodução social, reafirmando de maneira imperativa o significado das instâncias políticas e econômicas que consolidam a estruturação de uma crise orgânica sem precedentes, adverso inclusive, da conformação anterior sobre o qual compunha o bloco hegemônico do grande capital no segundo pós-guerra.

Vistos em sua totalidade, a prerrogativa da crise operada pelo neoliberalismo nos países latino-americanos não se restringe, como núcleo causal, tão somente à dificuldade de escassez ou ao problema do desemprego crescente na região, nem tampouco em decorrência da queda da taxa de lucro, mas ao efeito do esgotamento do padrão de financiamento público da economia capitalista.

Isso equivale a dizer que ao longo dos anos o modelo de financiamento estatal provocou um enorme déficit público, fazendo com que o acirramento das crises de valorização do capital comprometesse cada vez mais o endividamento do Estado brasileiro. $\mathrm{O}$ fato é que por detrás do financiamento de serviços sociais públicos, foram utilizados recursos para a estruturação da reprodução e expansão do capital em sua etapa de acumulação financeira.

Frente a isso, na medida em que o círculo do financiamento público, reprodução da força de trabalho e acumulação capitalista foi se aprofundando, a estabilidade desse modelo começa a oscilar, provocando um retraimento nos investimentos e na renda que deixam de ser cada vez mais nacionais, crescendo com isto, a internacionalização que retirou parte dos ganhos fiscais do Estado, deixando aos fundos públicos nacionais o ofício de permanecer articulando e financiando a reprodução do capital e a força de trabalho.

Tal processo tem sido acentuado pela forma contemporânea de acumulação por espoliação, na sugestiva indicação de Harvey (2004), cujo processo em curso, apresenta-se como um fenômeno arcaico de retomada da extração de mais valor na contemporaneidade, que se desenvolve como uma reprodução não expandida ou ampliada, tal como tratada por Marx (1983). Contraditoriamente é marcada pela especulação monetária rentável, de que é exemplo o capital portador de juros, convertido na forma social dominante no plano das economias internacionais e a tendência decrescente do valor de uso, abreviando de maneira drástica, o tempo de vida útil das mercadorias, cujas consequências se expressam por meio da precarização do trabalho e da destruição dos recursos naturais cada vez mais escassos (MÉSZÀROS, 2009).

E fato inconteste que a lógica do capital é desigual. Porém, as novas determinações da produção e reprodução dessa desigualdade e do processo de valorização do valor em seu circuito reprodutivo, caracterizada pela intensificação da precarização estrutural do trabalho e por um excesso de população sobrante (MARX, 1983), que não consegue inserção no mercado de trabalho, ou possui atividades cuja extração de mais valia ocorre de forma acentuada, faz com que a exploração da força de trabalho nesse início de século ocorra de modo extremamente degradante.

Neste sentido, as medidas de enfrentamento da crise geraram a necessidade de recomposição e ajuste entre as forças produtivas e os aparelhos de hegemonia, que demandam uma nova forma de reestruturar a produção, flexibilizando sobremaneira, o mundo do trabalho e a sua divisão social e técnica, por meio da implementação de mecanismos sócio-políticos que assegurassem a sua reprodução. 
Pois bem, essa crise tem de fato proporções devastadoras que demonstram inclusive, a atualidade do pensamento de Marx, na medida em que a lei do valor trabalho se fortalece e adquire dia após dia maior vigência.

Ao fim e ao cabo, esse cenário traduz mutações no interior do estágio monopolista e configura um novo momento na conformação do bloco histórico. Nela, a realidade se torna mais complexa, porque a fase de expansão e concentração do capital, levado às ultimas consequências pela internacionalização da produção, alterou o padrão de acumulação baseado na apropriação do trabalho não pago, induzindo a burguesia a redefinir suas estratégias de monopolização em escala planetária, cujo rentismo se torna a norma geral para a produção da riqueza, por meio de um amplo consenso social, onde a esfera financeira passa a ser determinante para as novas regras em escala mundial.

As rápidas mudanças do capital financeiro produziram uma diversificação de articulação de interesses sob a forma de lobbying e especulação sem precedentes, em que negócios nas áreas de câmbio, ações, bônus, títulos das dívidas públicas e derivados em geral se desenvolveram numa rapidez muito maior que as atividades produtivas e comerciais. A produção de valor gerado nessa área tem desacelerado o investimento de empresas produtivas, que na impossibilidade de gerar lucros, nas mesmas proporções que a área financeira, se veem obrigadas a realocar parte de seus recursos para o setor financeiro, comprometendo a sua atividade primária.

Nos exames de Marx (1983), no livro III de O Capital, pode-se verificar uma análise originária a respeito do capital rentável, identificado pelo autor sob a forma de capital bancário, dívida pública e capital acionário, que na época expressavam as determinações mais desenvolvidas do processo de acumulação em seu tempo.

Nas suas lições sobre a lei do valor, Marx (1983) demonstra todo o métier do processo de transformação do dinheiro em capital, que passa desde a produção do excedente econômico, identificado em sua grandeza como mais valor, extraídas da produção e circulação de mercadorias, até a forma específica assumida pelo capital como portador de juros, definido com suas próprias palavras, como um "capital vadio à espera de aplicação" (MARX, 1983, p. 732).

Os leitores dessa tradição teórica sabem que o dinheiro se converte em capital na medida em que se vincula ao movimento total do capital, sendo, portanto, na forma inicial dinheiro, que se gesta o processo capitalista de produção.

Como deduz Marx (1988), o capital-dinheiro na forma de juros não passa pelo circuito da produção, ou seja, não passa pela obtenção do lucro e exploração da força de trabalho e da capacidade extraordinária de reprodução, que nele entram pelo metabolismo: à medida que o trabalhador cria riqueza, esta se torna uma força do capital. De fato, no capitalismo financeiro o dinheiro que gera dinheiro, como valor que se valoriza a si mesmo é a forma mais reificada do capital.

Diz-se então, que as necessidades vitais do capital se renovam e as formas históricas possíveis de garantir a acumulação assumem características diversas, redefinindo a composição do polo hegemônico da burguesia nos países centrais.

$\mathrm{Na}$ literatura crítica das últimas décadas, esse processo deletério e polimorfo do regime mundial de valorização financeira tem sido problematizado por diversos teóri-

[...] o Brasil experimenta, no transcurso do século XXI, uma configuração política peculiar, com o ensaio neodesenvolvimentista (SINGER, 2016) que culmina com a tentativa lulista de instituir um tipo de economia política de caráter progressista e retributivo, sem alterar os pilares centrais da macroeconomia neoliberal consolidada no período anterior, resultando, em última instância, em uma experiência fracassada nos marcos do capitalismo dependente e periférico, em razão da própria posição subalterna em que o país ocupa na divisão internacional do trabalho sob o domínio do capital financeiro imperialista. cos do campo marxista, os quais não cabem fazê-lo aqui.

Importa saber que a dimensão financeira como locus privilegiado do funcionamento do capitalismo nas circunstâncias atuais, metamorfoseia-se sobre novos contornos, sem alterar as suas determinações gerais, 
fazendo avançar as linhas de força de um novo padrão de acumulação: flexível do ponto de vista produtivo, expandido através do fenômeno da financeirização e ideologicamente neoliberalizado.

Em sua crítica à economia política, Marx (1983, p. 191) nos ensina que "a produção de mais-valia ou a geração do excedente é a lei absoluta desse modo de produção." Mas também nos alerta para o processo de concentração de capital que não é outra coisa, senão o processo de reprodução ampliada do capital, onde a cada novo ciclo de produção aumenta o valor acumulado nas mãos do proprietário dos meios de produção, gerando assim uma concentração cada vez maior de capitais.

Portanto, a dinâmica da acumulação, como sistema de concentração e centralização do capital, que leva inevitavelmente à produção dos monopólios, tão bem analisada por Lenin (2007) e identificada de Imperialismo como etapa superior do capitalismo, elevada em sua potência máxima é reposta à ordem do dia, sob a hegemonia da oligarquia financeira mundial.

[...] é o protagonismo que a propriedade e o rentismo assumiram, bem como o alojamento dessa posição de exterioridade à produção no seio da própria produção. Assim, a patologia congênita do capitalismo assentada na contradição entre capital e trabalho combina-se agora com as contradições que se originam da centralidade da ûnança: de um lado, a acumulação é lenta e, de outro, a ûnança é insaciável no nível de suas punções. (PAULANI, 2009, p. 27).

Cumpre assim notar, que uma das consequências destrutivas desse processo é a subsunção incontestável do trabalho ao capital, refletida na intensificação do quadro de pobreza e desemprego nas nações dependentes e periféricas. Para os países latino-americanos, a cristalização desse quadro deletério se deu a partir da definição de um processo estrutural de reprodução da dependência e da crise, que corresponde ao maior endividamento dos Estados em função das medidas aplicadas pelos países centrais, voltadas para o enfrentamento da queda da taxa geral de lucro, levando os fluxos de capitais a migrar do centro para a periferia latinoamericana, tanto quanto os capitais de empréstimos, como os capitais voláteis especulativos.

A fim de hegemonizar o conjunto da economia, o polo financeiro captura também os Estados nacionais e sua política orçamentária, dirigida de maneira crescente para o pagamento dos serviços da dívida pública em prejuízo dos gastos em áreas de atividades sociais e produtivas (CHESNAIS, 1996).

Do ponto de vista estratégico, a quebra das barreiras econômicas por via de mecanismos políticos, consiste necessariamente na maior liberdade para o capitalismo impor as novas regras aos países periféricos, com destaque às funções do Banco Mundial e do Fundo Monetário Internacional - instituições financeiras reorientadas após o declínio do Bretton Woods - impondo inúmeras reformas e ajustes estruturais, particularmente no continente latino-americano, ocasionando saldos positivos para o capital.

Assim, a súmula política desses ajustes implicou na padronização do receituário neoliberal que se seguiu nos anos 2000, com cortes nas despesas com políticas sociais e investimentos, reforma da previdência, flexibilização do mercado financeiro para a presença de bancos internacionais, programa de privatizações, desregulamentação das relações trabalhistas (contrarreformas), entre outros.

Isso revela o movimento contraditório demarcado nesta quadra histórica, que numa leitura acrítica, tende a esconder a sua funcionalidade à ordem do capital, demonstrando mais do que nunca, sua capacidade transformista para efetivar a dominação, realizada mutatis mutantis num processo contínuo de passivização da ordem, cujo Estado se redireciona para organizar o consenso e articular as práticas classistas.

É portanto, através dessa relação pensada como movimento que vai do particular ao universal, no trânsito entre a economia e a política, que Gramsci (2002) reflete sobre a produção e organização do consenso através do qual a hegemonia se realiza, constituindo-se como direção moral e intelectual de determinados grupos que disputam interesses e alianças com outros grupos antagonicamente opostos. Em suas palavras:

[...] A produção e organização do consentimento é uma batalha competitiva cujo propósito é reproduzir e disseminar uma dada concepção de mundo, de modo que se torne 'historicamente verdadeira', o que por sua vez, significa sua transformação em senso comum. (GRAMSCI, 2002, p. 389).

O caminho sugerido por Gramsci (2002) $)^{3}$, indica que a crise embora constituinte do modo de produção e de troca - resultante da lei da queda da taxa de lucro - reflete profundamente a esfera política, uma vez que circunstâncias imediatas produzidas por situações econômicas, expressam conjunturas políticas estratégicas. Daí que no centro de suas reflexões, economia e política estabelecem um vínculo profundo.

Para o pensador sardo, a distinção entre crise orgânica e crise conjuntural é recorrente em sua análise, pois entende que a primeira é de maior amplitude e profundidade do que a segunda. Ou seja, a crise orgânica não está exclusivamente articulada à duração de uma crise conjuntural, pois é resultado de um conflito mais 
amplo entre a classe dominante e as demais frações de classe. Um tipo de crise que atinge as instituições, fazendo romper o bloco histórico vigente. Em suas palavras: "quando se verificam estas crises, a situação imediata torna-se delicada e perigosa, pois abre-se o campo às soluções de força, a atividades de potencias ocultas representados pelos homens providenciais ou carismáticos." (GRAMSCI, 2002, p. 60).

Por sua vez, levando em conta o momento atual, o que está em jogo é o rearranjo dos mecanismos político-institucionais a uma adequação homóloga e terminante às novas condições de acumulação do capital. Isso significa dizer que a crise atual é apenas uma manifestação particular radicada em uma crise orgânica do capitalismo, que se apresenta, sobretudo, como uma crise de hegemonia, revelando assim a incapacidade da burguesia dirigente em administrar as exigências da acumulação mundial do capital e os próprios fundamentos de adesão e consentimento do status quo.

Precisamente por isso, se faz consequente analisar as determinações na estrutura vigente da composição orgânica do capital - com suas próprias leis dialéticas e tendenciais - as quais exige da burguesia dirigente e dos governos de plantão, que os sustentam, uma série de respostas e ajustes para garantir a recomposição das condições de valorização do capital e, por conseguinte, a desvalorização da força de trabalho. Respostas, que significam no âmbito da movimentação burguesa a partir de seus projetos, impactos que incidem sobre os direitos do trabalho, no marco das conquistas democráticas (GOMES; ROJAS, 2017).

\section{A hegemonia regressiva do neodesenvolvimentismo brasileiro}

No modo de produção capitalista que articula em sua totalidade as relações entre economia e política, a forma que o desenvolvimento assume na região latino-americana expressa a universalização de relações concretas necessárias à produção e circulação de mercadorias para a reprodução ampliada do capital. Desse modo, ainda que o subdesenvolvimento não se constitua como uma particularidade exclusiva das relações de produção do capitalismo periférico, como fenômeno sócio-histórico, está subsumido à estrutura das relações sociais estabelecidas pelo capitalismo imperialista. Logo, compreender sua função social e dimensão contraditória requer situá-lo no contexto das formações sociais, como chave de análise para explicar a Era Lula e observar o movimento da história, certamente contribui para revelar o presente.

É possível dizer, em meio à vastidão de possibilidades e direcionamentos explicativos, que algumas questões nos parecem fundamentais para entender o momento analisado: por um lado, a estrutura da formação econômico-social brasileira e, por outro, as características particulares da crise capitalista atual. A interlocução com tais especificidades, exigiria pensar um pouco mais a fundo a natureza da revolução burguesa no Brasil (FERNANDES, 2006), a particularidade do Estado Nação, o caldo cultural disseminado pelas elites dominantes, o padrão adotado para a exploração da força de trabalho, a organização técnica da produção e a conformação das classes sociais em luta, o que supostamente não se faz nos limites de um artigo teórico.

Cabe, no entanto, como referência a suposição trabalhada no artigo sobre a análise do ciclo de "desenvolvimento desigual e combinado" (TROTSKY, 1967, p. 106), que associa características de períodos históricos diferenciados e é ilustrativa a nossa formação social, o que demonstra que na história do desenvolvimento capitalista brasileiro, a relação entre economia primário-exportadora, modernização e subdesenvolvimento é recorrente. Isso elucida, em última instância, um dos objetivos da pesquisa, ao tratar o caráter neodesenvolvimentista brasileiro nos marcos do neoliberalismo econômico.

Pois bem, em sintonia com as orientações do capitalismo mundial, pela via do receituário neoliberal, a realidade brasileira não foge à regra histórica de tendência periférica e subalterna em termos de desenvolvimento econômico. Na entrada dos anos 1990, considerando todas estas particularidades, Gonçalves (2013) sugere que se instaura no país o Modelo Liberal Periférico, conceito que explica a forma truncada de modernização do capitalismo a partir do Governo Collor (1990-1992) em diante. Os aspectos que resumem esse modelo são: (1) privatização; (2) liberalização; (3) desregulação; (4) subordinação e vulnerabilidade externa estrutural; (5) dominância do capital financeiro. Grosso modo, diz respeito à inserção passiva do Brasil na dinâmica de exigências da mundialização capitalista (BEZERRA; GOMES, 2015).

Nesse sentido, o discurso neodesenvolvimentista tentou revitalizar o padrão de intervenção do Estado na economia e na questão social, sobretudo no enfrentamento à pobreza, com políticas retributivistas de caráter neokeynesiano. Porquanto, as orientações econômicas que vinham desde o governo de FHC (1995-2003) foram aprofundadas no primeiro mandato do governo Lula (2003-2010) com ações voltadas para acalmar as mobilizações sociais e garantir a segurança dos grandes investimentos realizados pelas multinacionais. Estratégia que ganhou força no segundo mandato do governo petista, expressa no debate ideológico do neodesenvolvimentismo, impulsionada pela matriz econômica que tem no ativismo estatal a busca pela reindustrialização e nacionalização da economia, combinando investimentos entre o capital produtivo e financeiro. 
Ao analisar a literatura recente do Brasil, pode-se constatar que o modelo de desenvolvimento implantado na era lulo-petista é parte do programa neoliberal implantado por FHC, cuja particularidade se dá pela intervenção estatal em nome da garantia de uma estabilização de mercado e sustentabilidade social, por meio de programas de transferência de renda. A julgar pelo debate, sugere André Singer (2016, p. 24),

Pesquisadores polemizam em torno de um novo desenvolvimentismo de um social-desenvolvimentismo, procurando mapear as diferenças entre um e outro. De acordo com autores social-desenvolvimentistas, por exemplo, menos investimento público e mais subsídios ao investimento privado via desonerações, resultante de certa visão teórica novodesenvolvimentista, teria contribuído para o fracasso de Dilma. Ao contrário disso, autores novodesenvolvimentistas atribuem os problemas ao descaso com a austeridade fiscal, o que poderia ser atribuído ao social-desenvolvimentismo.

Também na avaliação de Sampaio Jr. (2012), o novo desenvolvimentismo é a expressão usada para designar a nova fase dos países da América Latina, que buscam conciliar industrialização, modernização e aumento de investimentos em políticas econômicas com equidade social. Uma versão mais controlada do neoliberalismo que durante os mandatos de Lula, se expressou por meio de mudanças no modo de regulação econômica, com vistas a eliminar os obstáculos deixados pela era FHC, assegurando juridicamente os novos processos do aparato estatal e privado, sem o risco de desestabilização política.

A propósito, pesquisas do Instituto Brasileiro de Geografia e Estatística (IBGE) (2015) revelam que houve no Brasil um crescimento de $4,1 \%$ do consumo das famílias em todas as classes sociais, notadamente aquelas de baixa renda, forjadas através da valorização do salário mínimo, dos incentivos com os programas de transferência de renda e uma conjuntura favorável ao rendimento do trabalho, com ganhos salariais. De fato, "[...] sabemos que durante os governos de Lula da Silva, 2,1 milhões de empregos formais foram criados no país todos os anos. Desses, dois milhões remuneraram até 1/5 salário mínimo." (BRAGA, 2012, p. 56).

Para se consolidar do ponto de vista da legitimação social, o neodesenvolvimentismo incorpora elementos de incidência social, política e econômica que estiveram ausentes no período anterior. Entre esses: a) recuperação do salário mínimo, aumento dos postos formais de trabalho e políticas de transferência de renda para as camadas mais pauperizadas; b) elevação do fundo orçamentário do Banco Nacional de Desenvolvimento Econômico e Social (BNDES); c) política externa de suporte às grandes empresas brasileiras ou instaladas no país para exportação de mercadorias e de capitais; e, por fim, d) uma política econômica de cariz anticíclico, medida para manter a demanda agregada em contextos de crise (BOITO JÚNIOR; BERRINGER, 2013; BEZERRA; GOMES, 2015).

É necessário enfatizar, que os dois mandatos de Lula (2003-2010) não são unívocos ou de mero continuísmo. Como advertem Boito Jr. e Berringer (2013), o primeiro foi marcado por uma tática defensiva para não hostilizar o capital financeiro internacional, apregoada na célebre Carta ao Povo Brasileiro (LEIA..., 2002). O segundo mandato, se sobressai pelo grosso investimento na criação e no fortalecimento de grupos econômicos nacionais, elevando o quantum de créditos e subsídios à disposição desses setores específicos, com destaque àqueles voltados ao processamento de produtos agrícolas, o que faz com que o ensaio neodenvolvimentista se dê pela via clássica do processo de reprimarização da economia, elemento comum ao conjunto das economias dependentes latino-americanas.

Para tanto, as circunstâncias da conjuntura internacional foram contundentes para a condução da matriz econômica da Era Lula. Gonçalves (2013), ao considerar as determinações do ciclo econômico internacional, avalia que há melhoras nos indicadores de nossa vulnerabilidade externa conjuntural, em especial, até 2008, quando explode a crise financeira nos Estados Unidos, tencionando assim, o rápido ciclo de crescimento no Brasil que colapsou, notadamente a partir de 2014.

Começou-se daí a generalização mais forte do ajuste fiscal, notadamente quando foram anunciados os cortes no orçamento federal em 2015, um montante de R \$ 69.946 bilhões do Orçamento Geral da União, como justificativa para equilibrar as contas públicas do país (AJUSTE..., 2015).

Diante do argumento de que era preciso fazer mudanças estruturais, passaram a crescer a grita de analistas econômicos e políticos por um pacote de medidas anti-crise, atualizando a agenda neoliberal contra os direitos dos trabalhadores e as pautas democráticas. E o resultado do ajuste não poderia ser mais desastroso e as consequências incalculavelmente tão perversas. Todos os índices registram aumento do desemprego, redução de postos de trabalho, encolhimento dos empregos no setor formal, jogando milhões de trabalhadores para a informalidade, altas nas taxas de juros, corte nos gastos em seguridade pública e nas políticas sociais de um modo geral; consequentemente flexibilizando direitos e depauperando a ínfima rede de proteção social que havia no país. 
Não é à toa que o Brasil é um dos países mais desiguais do mundo, como aponta o estudo publicado em 2015, O topo da distribuição de renda no Brasil: primeiras estimativas com dados tributários e comparação com pesquisas domiciliares 2006-2012, que apresenta uma série de indicadores de desigualdade com base nas declarações de imposto de renda da pessoa física. A pesquisa mostra que os $5 \%$ dos mais ricos da população brasileira concentravam naquele ano $44 \%$ da renda total, afirmando:

Os mais ricos apropriam-se de uma parcela substantiva da renda total, sem mudanças claras entre 2006 e 2012. [...] Nesse período, em média, o $0,1 \%$ mais rico recebeu quase $11 \%$ da renda total, o que implica que sua renda média foi quase 110 vezes maior do que a média nacional. O $1 \%$ mais rico, incluindo esse $0,1 \%$, apropriou-se de $25 \%$, e os $5 \%$ mais ricos receberam $44 \%$, quase a metade da renda total. (MEDEIROS; SOUZA; CASTRO, 2015, p. 18).

Esses dados guardam uma abissal proporção se comparados com os indicadores de transferência de renda, notoriamente investidos no período neodesenvolvimentista brasileiro, demonstrando outra contradição velada da Era Lula: a de que houve redução da pobreza entre 2006 e 2012, mas que não impactou na diminuição da desigualdade entre os grupos mais pobres da população, uma vez que os índices não foram suficientes para alterar a distribuição completa pela magnitude em que a renda é concentrada nos mais ricos.

Assim, o avanço que se processa nessa reflexão é inequívoco, sobretudo quando se faz menção ao lulopetismo, que ao compor uma base de sustentação governista, acabou por rifar a própria matriz econômica retributiva que defendia. Portanto, considerada a conjuntura atual problemática para a garantia dos marcos constitucionais dos direitos dos trabalhadores, referida ao processo retardatário da emancipação e autonomia política brasileira, vê-se aí o nó górdio da questão, agudizada pelos marcos da luta de classes.

Recordem-se os leitores, que a partir de 2005, o governo Lula opta por uma tática que Nobre (2013, p. 103) classifica de "ocupação pela esquerda do pemedebismo", que seria a renúncia da direção política dominante antes do mensalão à adesão das supermaiorias parlamentares, conformando-se de uma vez por todas à ideologia da governabilidade.

Nessa perspectiva, as eleições de 2014 apareceram como um momento de articulação política das forças de classe em presença, jogando um papel importante na adequação tática aos problemas colocados pela situação de crise.

Paradoxalmente, com os desdobramentos da crise no Brasil, sugerem os mais ortodoxos liberais que é impossível resolver a crise fiscal do Estado, enquanto saúde/educação e previdência/seguridade precisarem de verbas obrigatórias.

Tais tendências demonstram um quadro desolador. E ainda que a hegemonia lulo-petista tenha se configurado pela estabilização de forças que entrecruzam o terreno da dominação e da direção do processo social, ao fim e ao cabo, ficaram evidentes que as alianças, os arranjos políticos e os interesses das frações de classe no poder, na captura do jogo de forças que influenciam a dinâmica governista no Brasil, não foi capaz de apontar uma saída para a crise.

Forcejada em meio a um contexto de crescimento econômico conjuntural, tomaram para si concepções neodesenvolvimentistas como modalidade de regulação estatal para enfrentar a atual crise do capital.

\section{Considerações finais}

O fenômeno político-econômico do neodesenvolvimentismo e da Era Lula continuam como objeto de debates instigantes no interior das ciências sociais. O principal desafio da pesquisa, traçado nas linhas gerais desse artigo foi de articular as análises sobre a história recente do país às suas particularidades históricoestruturais, o que exigiu recuperar o pensamento social crítico brasileiro e latino-americano.

Com lucidez da complexidade dos aspectos que envolvem o tema e também a noção das limitações analíticas contidas neste artigo, arriscamos indicar que o lulo-petismo foi marcado pela dialética entre continuidades e rupturas nos marcos da quadra histórica neoliberal. Inserido num pacto essencialmente conservador, a hegemonia lulista reatualizou o mito da conciliação entre as classes sociais, não tocando em nenhuma das dimensões estruturais do país, reatualizando, assim, o caráter periférico e dependente do desenvolvimento capitalista brasileiro.

Ao tempo em que se costurou uma composição de parcelas significativas dos trabalhadores e influentes frações da burguesia, os ganhos foram estrondosos e indiscutivelmente superiores em relação aos primeiros. Em suma, como afirmado no percurso do artigo, a agenda dessa proposta consiste em combinar a elevação dos índices de crescimento econômico e avanços no processo de distribuição de renda que não tocaram na fatia do bolo (BEZERRA; GOMES, 2015). 
Por fim, em meio a um contexto de crescimento econômico conjuntural, o lulo-petismo apostou na criação de uma matriz econômica desenvolvimentista como estratégia para enfrentar a crise orgânica do capital. A tendência histórica já comprovada é que essa tentativa brevemente regride e, portanto, colapsa.

\section{Referências}

AJUSTE fiscal: governo anuncia corte de 69,9 bilhões de reais do orçamento. Carta Capital, 22 maio 2015. Disponível em: <https:// www.cartacapital.com.br/economia/ajuste-fiscal-governo-anuncia-corte-de-69-9-bilhoes-de-reais-do-orcamento-6830.html>. Acesso em: 13 maio 2016.

BEZERRA, L.; GOMES, C. O neodesenvolvimentismo nos governos Lula e as particularidades do capitalismo brasileiro: reflexões iniciais do processo de pesquisa. In: ENCONTRO DE GRUPOS DE ESTUDOS E PESQUISAS MARXISTAS, 7., 2015, Campina Grande, PB. Anais... Campina Grande, PB, UFCG, 2015. Disponível em: <http://epmarx-anais.blogspot.com.es/2015/09/anais-do-viiepmarx-2015-volume-1.html >. Acesso em: 14 fev. 2017.

BOITO JÚNIOR, A.; BERRINGER, T. Brasil: classes sociais, neodesenvolvimentismo e política externa nos governos Lula e Dilma. Revista de Sociologia e Política, Curitiba, v. 21, n. 47, p. 31-38, set. 2013. Disponível em: <http://www.scielo.br/pdf/rsocp/v21n47/ 04.pdf>. Acesso em: 14 fev. 2017.

BRAGA, R. A política do precariado: do populismo à hegemonia lulista. São Paulo: Boitempo, 2012.

BRASIL DEBATE et al. (Org.). Por um Brasil justo e democrático. Mudar para sair da crise: alternativas para o país voltar a crescer. São Paulo, v. 1, set. 2015. Disponível em: <https://fpabramo.org.br/publicacoes/wp-content/uploads/sites/5/2017/05/ porumbrasiljustoedemocratico-vol-01_0.pdf $>$. Acesso em: 22 set. 2016.

CARCANHOLO, M. D. Dependencia, super-explotación del trabajo y crisis. Una interpretación desde Marx. Madrid: Maia, 2017. CHESNAIS. François. (Org). A mundialização financeira: gênese, custos e riscos. São Paulo: Xamã, 1998.

FERNANDES, F. Revolução burguesa no Brasil: ensaio de interpretação sociológica. São Paulo: Globo, 2006.

GOMES, C. M. C. O neodesenvolvimentismo brasileiro e o programa de reformas de combate à pobreza na era Lula. Projeto de Pesquisa (edital MCTI/CNPq n. 14/2014). João Pessoa, UFPB, 2014.

; ROJAS, G. Governos, Crise orgânica e seus impactos na América Latina. Conservadorismo e Resistências na América Latina. Em Pauta, n. 39, v. 15, p. 17-32, $1^{\circ}$ semestre 2017. Disponível em: <http://www.e-publicacoes.uerj.br/index.php/revistaempauta $>$. Acesso em: 10 set. 2017

GONÇALVES, R. Desenvolvimento às avessas: verdade, má-fé e ilusão no atual modelo de desenvolvimento. Rio de Janeiro: LTC, 2013.

GRAMSCI, A. Os cadernos do cárcere. Rio de Janeiro: Civilização Brasileira, 2002. v. 3.

HARVEY, D. O novo imperialismo. São Paulo: Loyola, 2004.

IBGE. Síntese de indicadores sociais: uma análise das condições de vida da população brasileira. Coordenação de População e Indicadores Sociais. Rio de Janeiro: IBGE, 2015. Disponível em: <https://biblioteca.ibge.gov.br/visualizacao/livros/liv95011.pdf>. Acesso em: 22 fev. 2016.

LEIA íntegra da carta de Lula para acalmar o mercado financeiro. Folha de São Paulo, São Paulo, 24 jun. 2002. Disponível em: <http:/ /www1.folha.uol.com.br/folha/brasil/ult96u33908.shtml>. Acesso em: 20 jun. 2015.

LENIN, V. I. U. O Imperialismo, etapa superior do capitalismo. Campinas, SP: FE/UNICAMP, 2011. Disponível em: <http:// ujs.org.br/index.php/noticias/o-imperialismo-etapa-superior-do-capitalismo-lenin/>. Acesso em: 12 jun. 2015.

LUZ, F. R. da. A Hegemonia neoliberal lulista. 2015. 153 f. Dissertação (Mestrado em Serviço Social) - Universidade Federal da Paraíba, João Pessoa, 2015.

MARX, K. O Capital: crítica da economia política. Livro 1: O processo de produção do capital. São Paulo: Abril Cultural, 1988. v. 1. . O Capital: crítica da economia política. Livro 3: O processo global da produção capitalista. Rio de Janeiro: Civilização brasileira, 1983. v. 5

MEDEIROS, M.; SOUZA, P. H. G. F. de; CASTRO, F. A. de. O topo na distribuição de renda no Brasil: primeiras estimativas com dados tributários e comparação com pesquisas domiciliares (2006-2012). DADOS - Revista de Ciências Sociais, Rio de Janeiro, v. 58, n. 1, p. 7-36, 2015. Disponível em: <http://www.scielo.br/pdf/dados/v58n1/0011-5258-dados-58-1-0007.pdf>. Acesso em: 12 abr. 2016.

MÉSZÀROS, I. A crise estrutural do capital. São Paulo: Boitempo, 2009.

NOBRE, M. Imobilismo em movimento: da abertura democrática ao governo Dilma. São Paulo: Companhia das Letras, 2013.

PAULANI, L. M. A crise do regime de acumulação com dominância da valorização financeira e a situação do Brasil. Estudos Avançados, v. 23, n. 66, p. 25-39, 2009. Disponível em:< http://www.scielo.br/pdf/ea/v23n66/a03v2366.pdf>. Acesso em: 13 out. 2016.

SAMPAIO JÚNIOR, P. de A. Desenvolvimentismo e neodesenvolvimentismo: tragédia e farsa. Serviço Social e Sociedade, São Paulo, n. 112, p. 672-688, out./dez. 2012.

SINGER, A. A (falta de) base política para o ensaio desenvolvimentista. In: Lulismo: a que ponto chegamos? São Paulo: Boitempo, 2016. p. 21-54. .; LOUREIRO, I. (Org.). As contradições do 
. Os sentidos do lulismo: reforma gradual e pacto conservador. São Paulo: Companhia das Letras, 2012.

TROTSKI, L. História da Revolução Russa. Rio de Janeiro: Saga, 1967. v. 1.

\section{Notas}

1 De acordo com Luz (2015, p. 22) se refere "[...] ao modus operandis, resultado do transformismo pelo qual passou o Partido dos Trabalhadores e os movimentos sociais e sindicais que lhe dão sustentação popular (CUT, MST, UNE, CNBB, etc.). Trata-se da forma como os setores da classe trabalhadora organizada vai se relacionar com os governos Lula-Dilma.“"

2 Conforme assinala o economista Marcelo Carcanholo (2017, p. 42), "Los derivados son instrumentos financieros constituidos (precio y lógica de transacción en el mercado) con base en otros activos (mercancías o instrumentos financieros que les sirven de referencia. Se tiene aquí la base para el crecimiento exponencial de títulos de deuda con base en títulos de deuda, o sea, expansión de la masa de capital ficticio en función de la ya existente; derechos de apropriación sobre un valor aún no producido."

3 O conceito de crise orgânica encontra-se ao longo das notas dos cadernos gramscianos, com destaque para o Caderno 13 [1932-1934,] notas §17 (analise das relações de força) e notas $§ 23$ (estrutura dos partidos políticos nos períodos de crise orgânica) (GRAMSCI, 2002).

\section{Claudia Maria Costa Gomes}

claudiac_gomes@hotmail.com

Doutorado em Serviço Social pela Universidade Federal de Pernambuco (UFPE)

Professora Associada do Departamento de Serviço Social e do Programa de Pós-Graduação em Serviço Social da Universidade Federal da Paraíba (UFPB)

\section{UFPB}

Cidade Universitária, s/n - Castelo Branco III

João Pessoa - Paraíba - Brasil

CEP: 58.051-085 